\title{
Analysis of the Impact of the Crowbar Protection on Short-Circuit Level and Quality Index
}

\author{
Piedy Del Mar Agamez Arias ${ }^{1,2}$ and Marcus Vinicius Alves Nunes ${ }^{1}$ \\ ${ }^{1}$ ITEC- Technology Institute - Department of Electrical Engineering, Federal do Pará University \\ Parque de Ciência e Tecnologia do Guamá 66077-830 Guamá (Brazil) \\ ${ }^{2}$ INESCTEC - Instituto de Engenharia de Sistemas e Computadores, Tecnologia e Ciência \\ PDEEC - Doctoral Program in Electrical and Computer Engineering, University of Porto (Portugal) \\ Phone number: +351 933242024, e-mail: piedy.a.arias@inesctec.pt; piedydelmar@hotmail.com
}

\begin{abstract}
The accelerted growth of power generation from renewable sources have taken great importance for planning and operation of distribution network due to the power supplied to the system from these sources. The development of technologies that allow exploiting the renewable resources has led to increase of distributed generation (DG) mainly at the distribution level. The integration of these DGs provides advantages to the power system as diversification of energy market and reduction of $\mathrm{CO} 2$ emissions. Nevertheless, disadvantages are also present like variations of short-circuit current levels, which affects the protections coordination by causing undesirable interruptions of the power supply to users that should not be affected. This paper analyses the impact on protection system and quality service index in a radial distribution network caused by the variation of short-circuit current level after the integration of a Doubly Fed Induction Generator (DFIG) under consideration of crowbar protection (disconnect/reconnect). As study case, an IEEE 13node test system was used to simulate a balanced short-circuit and to evaluate the impacts on protection system and quality service index.
\end{abstract}

\section{Key words}

Radial Distribution System; Distribution System Protection; Protection Coordination; Quality Service Index; Distributed Generation.

\section{Introduction}

Until recently, the power generation were located in specific points close to energy sources, as a consequence the power supplied to the final consumers needed a strong transmission system in order to transport the energy along considerable distances up to distribution systems [1]. Recently, the traditional electric power system has been modified because the power generation has been located close to the final consumers. This new generation scheme close to final consumers leading a growth of distributed generation or dispersed generation.
The integration of these new power generation from renewable energy sources such as photovoltaic, wind, biomass, fuel cells, among other, have become a worldwide trend. These power sources are frequently integrated to the network to supply non-interconnected areas, to strengthen the network in areas with conventional electrification and to support the energy delivered to the distribution network.

Currently, around $17 \%$ of world population still lacks access to electrical power system [2]. The main reason is that the investment involved in start-ups of new power generation projects, electrification of specific areas (frequently, rural areas) and energy demand, is not compensated by the incomes of the companies at the short or medium term. In this context, the potential power generation identified from renewable sources becomes a promising alternative to electrify more areas. The figure 1, show details of the global potential for power generation from renewable sources.

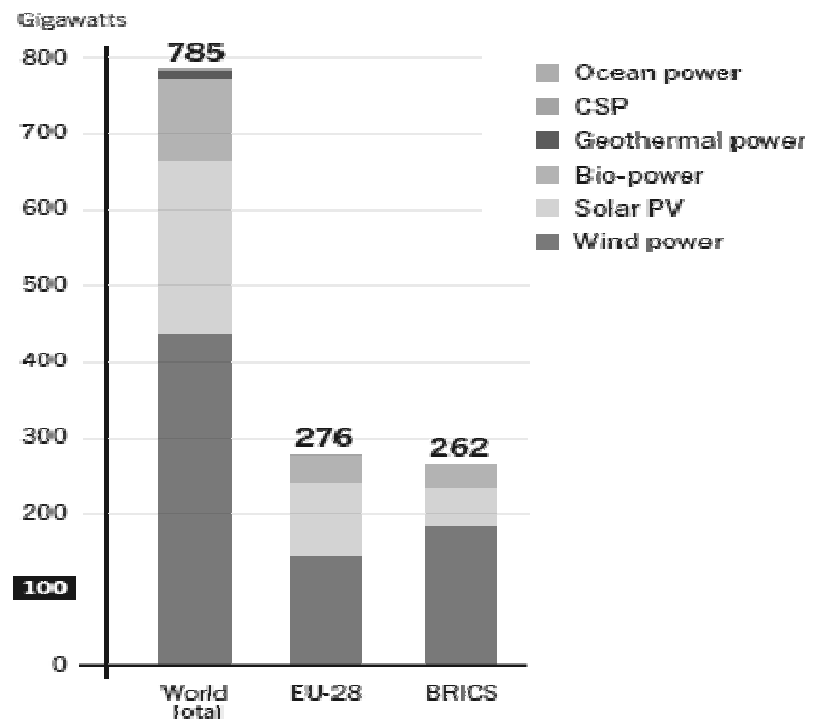

Figure 1. Power generation potential by type of renewable source.

Font: [2] 
As shown in the Figure 1, the potential power generation form wind and solar sources have the greatest potential participation, for this reason, these sources have been chosen by several researchers as the main renewable energy sources to be integrated to the network. In [2] is explained that Latin America has experienced the fastest growth on wind and solar power generation. Brazil is the one of leaders in integration of these sources in their networks, entering within the top 10 countries with better wind power generation potential and installed capacity.

The integration of power generation from renewable energy sources to the distribution network provides advantages to the power system as strengthening the electric system without requiring the expansion of the transmission system, decreasing the transmission losses and $\mathrm{CO} 2$ emissions, among others [3]. The disadvantages are focused on technical aspects of the network, such as the variation of the voltage profile close to the coupling point of the DG, changes in short-circuit current levels, variation of harmonic distortion and modifications of operational conditions of the distribution network [4]-[7].

Among the aforementioned disadvantages, the changes in short-circuit current levels highlight because when DGs are integrated in the distribution network, their current level changes affect the protection scheme used that network. Frequently, the protections coordination in distribution networks with radial topology are proposed considering two aspects related to short-circuit current: (i) the current flow in one direction (from substation) and, (ii) the current level relies of short-circuit power imposed by the substations and fault location [4].

The influence of the DG integration on protections coordination produces undesired power interruption to final consumers. This interruption causes an impact on the quality service index monitored by distribution companies in order to evaluate the service continuity [8]-[10]. In this sense, researcher has presented some proposals to identify and to mitigate the impact caused on protection system by DGs integrated in the distribution networks. Relevant research proposed:

- Analyse the impact caused by DGs integrated to radial distribution networks and to identify the relation with wrong operations and erroneous load cuts on healthy parts of the network [5].

- Develop a control strategy to keep the DFIG connected to the network during a fault and to maintain the synchronism. For that, it was necessary to limit the rotor current including a bypass resistor (crowbar protection) connected between the rotor and the converter [11].

- Study the DFIG behaviour to determine the shortcircuit currents (focussed on the first peak value) supplied to the network under faults conditions. An equation were determined to know the appropriate bypass resistor (crowbar protection) value in order to mitigate overvoltage and to limit the rotor current [12].
- Develop a control strategy to mitigate the DGs contribution (connected through inverters) to shortcircuits currents. It considers to limit the current supplied during network faults based-on the voltage level at the coupling point [1].

- Implement and compare 2 control strategies for the DFIG control in order to identify the impacts caused by the DFIG on power system under voltage sags condition [13].

- Monitor the distribution network to identify the critical coordination margins in real-time to guarantee the recloser-fuse scheme. The real-time monitoring allows disconnect the DG with significant contribution to short-circuit current from the network by gate turn-off thyristors the DG [14].

- Set two curves with inverse time-current characteristic in the overcurrent protection devices installed in the meshed distribution network with DG. The dual setting allows a fast and reliable protection system by avoiding undesirable DGs disconnections during fault conditions [15].

- Use algorithms based-on symmetrical component to suppress the voltage measurement required by the directional protection device installed in distribution network. One of these algorithms establish a ratio of negative sequence current and zero sequence current $\left(\mathrm{I}_{2} / \mathrm{I}_{0}\right)$ at the fundamental frequency. The other algorithm establish a ratio of zero sequence current and positive sequence current $\left(\mathrm{I}_{0} / \mathrm{I}_{1}\right)$. These ratios defining operational areas (forward and reverse) [16].

The efforts made to minimize and to mitigate the impacts caused by DG contribution to short-circuit currents were evidenced in researches. Nevertheless, the implementation of some of these aforementioned proposals represent the investment in new protection devices, substation equipment or communications and protection schemes by the distribution companies.

The aim of this paper is to analyse the impacts on the feeder-recloser-fuse protection scheme and quality service index caused by a fault in a distribution network with DFIG integrated. The sections are organized as follows: The DFIG modelling, protection scheme and information about quality service index are discussed in Section II. Section III discusses the simulations and result. Finally, in section IV conclusions are presented.

\section{Metodology}

The potential power generation from sources as wind and solar have led to connect to the networks, generation technologies that adapt to the characteristics of the source. In the case of wind generation, the available technologies are: synchronous generator with winding rotor or permanent magnet rotor; induction generator and doubly fed induction generator [17]. 
The figure 2 shows the wind power capacity integrated to the networks and the wind power installed during the last year in some countries. Note that among all Latin America countries, Brazil stands out by their efforts and take advantage of this energy resource.

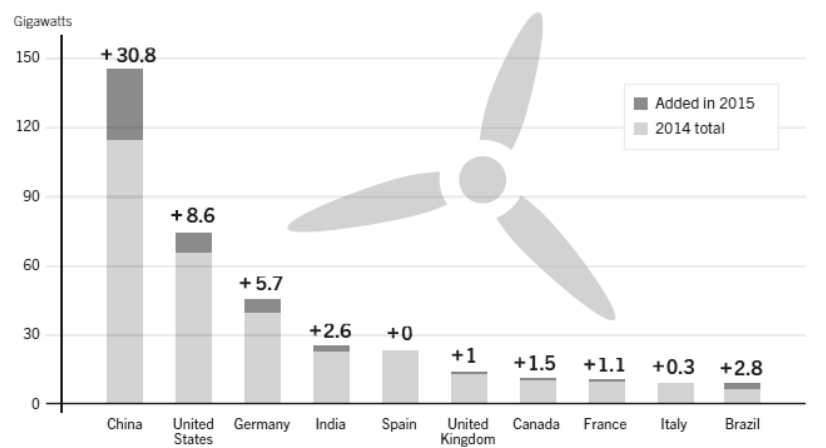

Figure 2. Wind Power Installed and Added Capacity by Country. Font: [2]

In order to reach the objective of this paper, the DFIG was the wind generators technology chosen. Since dynamic models of this generator type have been widely developed in the literature [11], [18]-[20], generator modelling will not be carried out in this work.

The DFIGs operates in variable speed. The control strategies adopted consider that the DFIG operates connected to the network through static converters. This imposes an economical advantage because reduce the cost of the machine [18] if compared with other technologies. Regarding of the technical aspect required to allow the integration of these generator type its indispensable highlight the ability to survive during voltage drops [21], because it is essential that during a fault the generator helps supporting the profile voltage of the network.

On the other hand, when a fault occurs in the network, the protection system should clear it. Typically, the protection scheme employed in radial topologies are feeder-recloserfuse or feeder/recloser-fuse. The device starting the feeder and the recloser are devices with programmable overcurrent protection functions and the fuses have a defined curve. To enable the protection scheme, the coordination is required between them. To solve this, is normal to consider that the contribution to short-circuit current comes from the substation because the sources are upstream. This approach ensures that during a fault the protection devices will act to eliminate it [22]. When DGs are integrated to the network that consideration should be checked because short-circuit current contributions comes from the substation and the DG.

Regarding to the interruptions or the energy service continuity, there is a quality service indicator which defined as the quantifiable representation about the performance of an electrical network. The goal of this indicator is to maintain desirable levels of continuity of the energy supplied to the consumers to determine the company performance (in contrast to setting values) during a cycle tariff review. This indicator is important because the companies have to do an obligatory payment by the energy that was not supplied to the final consumers.
In Brazil, this indicator is know as DEC (Duração Equivalente de Interrupção por Unidade Consumidora). The DEC represents the average time in which the consumer units were interrupted of an electrical network, during the observation period.

In [8], the DEC indicator is determined according to Equation 1.

$$
D E C=\frac{\sum_{i=1}^{N} C_{a}(i) \times t(i)}{C_{t}} \text { hours/users }
$$

Where:

$\mathrm{Ca}(\mathrm{i})$, number of consumers of the universe considered as affected by the interruption (i).

$\mathrm{t}(\mathrm{i})$, time duration, in hours and minutes, without electrical energy service (i).

i, number of interruptions considered, between 1 to $\mathrm{N}$. Where $\mathrm{N}$ is a number of interruptions during the assessment period.

$\mathrm{C}_{\mathrm{t}}$, total number of consumers of the universe under observation.

The measured interruptions taking account are the voltage discontinuities identified at any phases of the feeder with interruption time greater than 3 minutes. The short-time interruptions (less than 3 minutes), although it is also harmful to consumers, are not considered in the calculation of this indicators. The Figure 3 shows the hours of interruptions/users registered in Brazil for the last years. The straight line indicates the value expected to reach. The bars show the real values obtained at the end of the period.

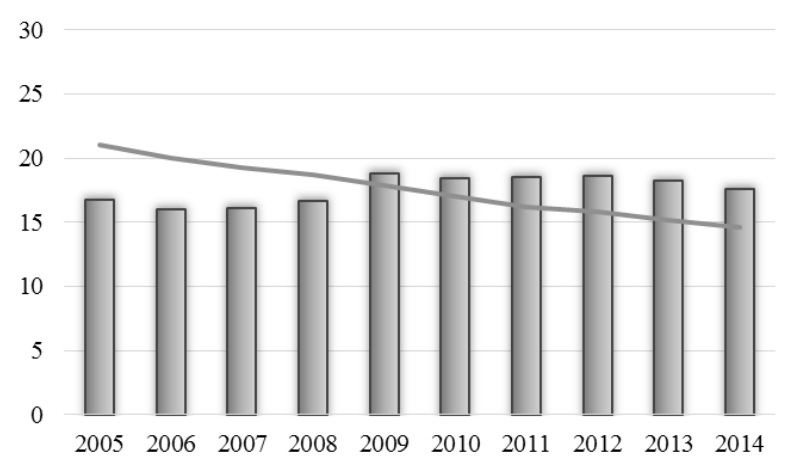

Figure 3. DEC Evolution in Brazil

Font: ANEEL

\section{Results}

In order to analyses the impact on protection system and quality service index in a radial distribution network caused by the variation of short-circuit current level after the DFIG integration, the IEEE 13-node test feeder system [23] has been simulated. For this network, a protection scheme feeder-recloser-fuse was proposed as follows: an overcurrent protection upstream to B632 (R1 modelled by numerical SIEMENS protection), a recloser upstream to B671 (R2 modelled by recloser NULEC) and 
a fuse in B680 (F1 with defined curve like 40K). The settings for the protection coordination were proposed evaluating the criteria as follows: conductor's capabilities, short-circuit current levels, coordination time around $160 \mathrm{~ms}$, maximum time to clear the fault and other specifications presented in [22]. The protection curves with very-inverse characteristic were chosen to guarantee the coordination (oriented to fuse saving scheme [24]) between protection devices.

Subsequently, some modifications were proposed to integrate the DFIG in B633 as shown in the Figure 4. Two operation cases for the DFIG were considered; CASE A, without the crowbar protection, so the converter remains connected to the rotor during the fault. CASE B, considering the connection of the crowbar protection during a fault, so it operates as an inductor generator.

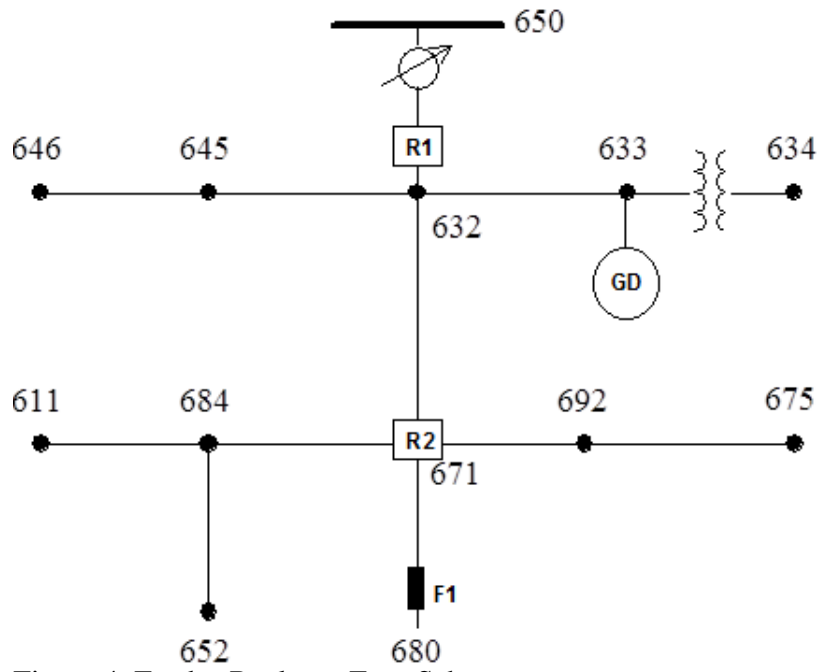

Figure 4. Feeder-Recloser-Fuse Scheme.

Simulations were carried out at balanced short-circuit conditions (fault impedance of $0,01 \Omega$, voltage drop of $85 \%$ at the DFIG coupling point and time fault about $150 \mathrm{~ms}$ ). The faults were simulated downstream of B680.

The figures 5, 6 y 7, shown the results obtained when a balanced short-circuit was simulated before the DFIG integration, after the DFIG integration CASE A, and after the DFIG integration CASE B, respectively.

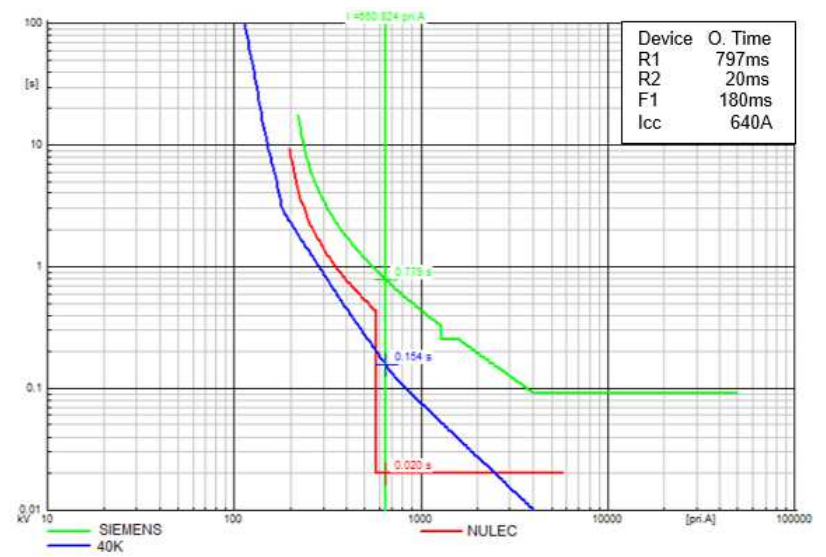

Figure 5. Short-circuit current level and operation time of the protection devices before the DGIF integration.

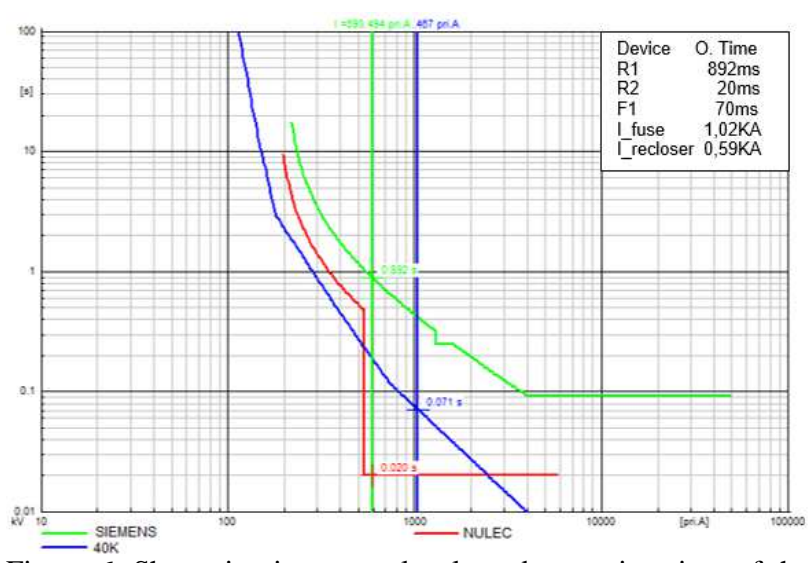

Figure 6. Short-circuit current levels and operation time of the protection devices after the DGIF integration CASE A.

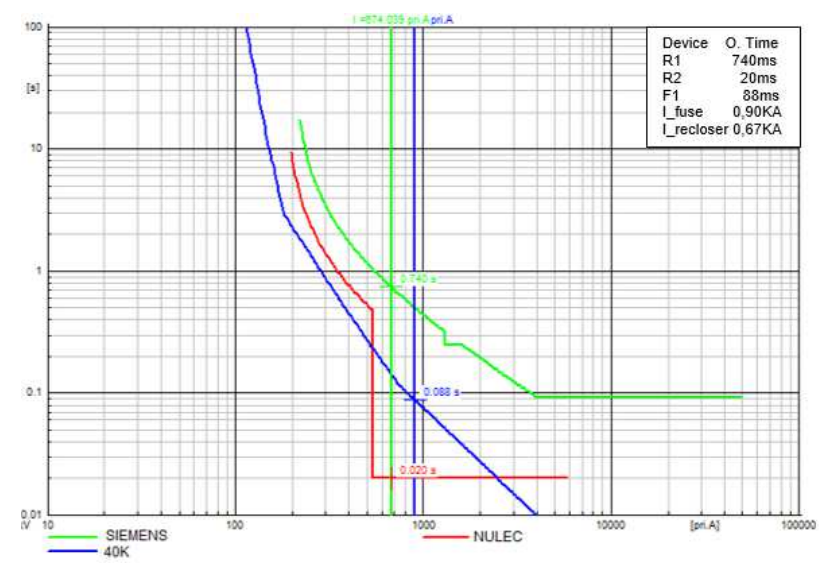

Figure 7. Short-circuit current levels and operation time of the protection devices after the DGIF integration CASE B.

As noted in Figure 5, the setting proposed guarantee the protection coordination between protection devices until maximum short-circuit current contributions from substation. After the DFIG integration, the Figures 6 and 7 , shown the increases of short-circuit current values and the variation in the current value measured by protection devices. These variations were caused by the DFIG contribution during a fault. The DFIG contribution to short-circuit current was greater for the CASE A than the CASE B. The resistance inserted to the rotor by the crowbar protection considered in the CASE B caused the difference.

Specifically for CASE A, as noted in the Figure 6, the current contribution from the substation decreases. Moreover, the new short-circuit current value at the point under analysis increases due to the DFIG contribution. This new short-circuit current value leads to protection miscoordination because the registered $\mathrm{R} 2$ and $\mathrm{F} 1$ current values were above the values obtained before the DFIG integration. The R2 and F1 miscoordination can produce a "simultaneous" action to clear the fault because the recloser trip and the fuse could also melt, as consequence undesirable interruptions to final consumers can occurs. In the other hand, the R1 and R2 devices kept the coordination. Nevertheless, is necessary to assess the backup times imposed by R1. 
Specifically for CASE B, as noted in the Figure 7, the current contribution from the substation decreases compared to the result shown in the Figure 5, but increases compared to the result shown in the Figure 6. Furthermore, the new short-circuit current value at the point under analysis increases respect to the result shown in the Figure 5 but decreases respect to the result shown in the Figure 6. The new short-circuit current value also leads to miscoordination protection because the registered R2 and F1 current values were above the values obtained before the DFIG integration. The R2 and F1 miscoordination can also produce similar result than in the CASE A. In the other hand, the R1 and R2 devices kept the coordination. Nevertheless, is also necessary to assess the backup times imposed by R1.

For both cases, the protection coordination should be evaluated with the DFIG integration at the distribution radial network because is necessary to check compliance with the coordination criteria.

Finally, analysing the R2 and F1 miscoordination could be obtained the scenarios showed in the Figure 8 for possible undesirable interruptions to final consumers.

\begin{tabular}{|l|l|c|c|c|c|}
\hline \multicolumn{2}{|c|}{ Event } & Between R2 and F1 & Interruption Time & Downstream F1 & Interrption Time \\
\hline 1 & Fault Occur's & \multirow{2}{*}{ R2 Tripping } & $\begin{array}{c}\text { Automatic Close } \\
\text { Time (less than 3min) }\end{array}$ & F1 doesn't melt & $\begin{array}{c}\text { Automatic Close } \\
\text { Time (less than 3min) }\end{array}$ \\
\cline { 1 - 2 } 2 & Automatic close of R2 & & & & \\
\cline { 1 - 2 } 3 & Fault Cleared & & &
\end{tabular}

After DFIG Integration, Case A.1

\begin{tabular}{|c|l|c|c|c|c|}
\hline \multicolumn{2}{|c|}{ Event } & Between R2 and F1 & Interruption Time & Downstream F1 & Interrption Time \\
\cline { 1 - 2 } 1 & Fault Occur's & R2 Tripping & $\begin{array}{c}\text { Automatic Close } \\
\text { Time (less than 3min) }\end{array}$ & F1 melting & $\begin{array}{c}\text { Time required to } \\
\text { chage the fuse (greater } \\
\text { than 3min) }\end{array}$ \\
\hline 2 & Automatic close of R2 & & & & \\
\cline { 1 - 2 } 3 & Fault Cleared & & &
\end{tabular}

After DFIG Integration, Case A.2

\begin{tabular}{|c|c|c|c|c|}
\hline Event & Between $\mathrm{R} 2$ and $\mathrm{F}$ & Interruption Time & Downstream Fl & Interrption Time \\
\hline \begin{tabular}{|l|l|}
1 & Fault Occur's \\
\end{tabular} & \multirow{2}{*}{ R2 Tripping } & Automatic Close & \multirow{2}{*}{ F1 doesn't melt } & Automatic Close \\
\hline \begin{tabular}{|l|l}
2 & Automatic close of R2 (\#1) \\
\end{tabular} & & Time (less than 3min) & & Time (less than 3min) \\
\hline \begin{tabular}{|l|l|}
3 & Fault Not Cleared \\
\end{tabular} & \multirow{3}{*}{ R2 Tripping } & & \multirow{3}{*}{ F1 melting } & \multirow{3}{*}{$\begin{array}{l}\text { Time required to } \\
\text { chage the fuse (greate } \\
\text { than } 3 \mathrm{~min} \text { ) }\end{array}$} \\
\hline \begin{tabular}{|l|l}
4 & Automatic close of $\mathrm{R} 2(\# 2)$ \\
\end{tabular} & & Time (less than $3 \mathrm{~min}$ ) & & \\
\hline \begin{tabular}{|l|l|}
5 & Fault Cleared \\
\end{tabular} & & & & \\
\hline
\end{tabular}

Figure 8. Users affected during a fault.

The CASES A.1/B.1 and A.2/B.2 are related to scenarios representing the action of $\mathrm{F} 1$ to clear the fault. These scenarios were created by the uncertainty associated to the miscoordination. The CASE A.1/B1 represent the scenario where R2 trips and the F1 melts. The CASE A.2/B2 represent the scenario where $\mathrm{R} 2$ trips and $\mathrm{F} 1$ does not melt and the fault remained in the network, for this reason, a new R2 trips is required. These cases represent scenarios occurred in real distribution networks. As can be noted, the miscoordination leads to worse the user perception about service (when, the interruption time is less than 3 minutes) and quality service index (when, the interruption time is greater than 3 minutes). The CASE A.2/B.2 are the worst cases because the final consumers downstream to $\mathrm{F}$ 1 perceive the energy absence twice.

\section{Conclusion}

The integration of power generation from renewable energy sources to the distribution network has modified the traditional electric power system because the power generation is located close the final consumers. This power decentralized generation is known as distributed generation or dispersed generation.

The DGs integrations in radial distribution networks provides advantages to the electric power system. Also, provide disadvantages as variations of short-circuit current levels. In this paper, simulations were carried out to analyse the impact caused by the DFIG integration on protection schemes. For this purpose, a balanced shortcircuit was assumed to evaluate the scheme feederrecloser-fuse (with fuse saving scheme).

The obtained results shown the protection coordination compliance with protection criteria before the DFIG integration. After the DFIG integration, short-circuit current at the fault point was greater for the CASE A than the CASE B. This was caused by the crowbar protection insertion. The contribution to short-circuit current from substation and from DFIG relies on the operational condition because the crowbar protection resistor change the equivalent resistance seen from the substation and from the DFIG.

Respect to the protection coordination it is necessary to be checked, because the increases in short-circuit current levels leads to deal with miscoordination problems. The miscoordination creates uncertainties scenarios related to the operation of the miscoordinated protection devices (in the CASES A and B was F1) and, the frequency and interruption time. Two scenarios were analysed for F1. In both cases, the user perception of service and the quality service index were affected by the registered undesirable interruptions. In contrast, in the results obtained before the DFIG integration only the user perception was affected by the fault clearance.

The negative effect on user perception and the quality service index caused by the aforementioned miscoordination problem, represent an important subject to the distribution companies because these companies are forced to make a payment by the energy not supplied to the final consumers. Specifically, the user perception is important when distribution companies want to know the user satisfaction by the service received.

\section{References}

[1] H. Yazdanpanahi, Y. W. Li, and W. Xu, "A New Control Strategy to Mitigate the Impact of InverterBased DGs on Protection System," IEEE Trans. Smart Grid, vol. 3, no. 3, pp. 1427-1436, 2012.

[2] REN21, "Renewables 2016 Global Status Report," Paris. Anu. ISBN 978-3-9818107-0-7, p. 272.

[3] N. Jenkins, R. Allan, P. Crossley, D. Kirschen, and G. Strbac, "Embedded Generation," United Kingdom: The Institution of Engineering and Technology, IET. ISBN: 9780852967744, 2000.

[4] R. F. Arritt and R. C. Dugan, "Review of the Impacts of Distributed Generation on Distribution Protection," 
IEEE Rural Electr. Power Conf. Asheville, USA, pp. 69$74,2015$.

[5] K. Vijeta and D. V. S. . Siva Sarma, "Protection of distributed generation connected distribution system," in 2012 International Conference on Advances in Power Conversion and Energy Technologies (APCET), 2012, no. Aug., pp. 1-6.

[6] F. M. Nuro and A. B. Arsoy, "Voltage Profile and Short Circuit Analysis in Distribution Systems with DG," IEEE Electr. Power Conf. Vancouver, Canadá, pp. 1-5, 2008.

[7] J. C. Gomez, J. Vaschetti, C. Coyos, and C. Ibarlucea, "Distributed Generation: Impact on Protections and Power Quality," IEEE Lat. Am. Trans., vol. 11, no. 1, pp. 460-465, 2013.

[8] ANEEL, "Procedimentos de Distribuição de Energia Elétrica no Sistema Elétrico Nacional - PRODIST, Módulo 8 - Qualidade da Energia Elétrica," vol. 1ra Versão. ANEEL, Brazil, pp. 1-53, 2008.

[9] CREG, "Metodología para el Cálculo de Servicio de Energía Eléctrica en Sistemas de Transmisión Regional y/o Distribución Local," Com. Regul. Energía y Gas, p. 59, 2004.

[10] CREG, "Resolución CREG 097 de 2008," Resolución CREG-097. Colombia, pp. 103-121, 2008.

[11] J. Morren and S. W. H. De Haan, "Ridethrough of Wind Turbines with Doubly-Fed Induction Generator During a Voltage Dip," IEEE Trans. Energy Convers., vol. 20, no. 2, pp. 435-441, 2005.

[12] J. Morren and S. W. H. de Haan, "Short-Circuit Current of Wind Turbines With Doubly Fed Induction Generator," IEEE Trans. Energy Convers., vol. 22, no. 1, pp. 174-180, 2007.

[13] M. B. C. Salles, "A Study on the Rotor Side Control of DFIG-based Wind Turbine during Voltage Sags Without Crowbar System," Int. Conf. Renew. Energy Res. Appl. (ICRERA), 2012, 2012.

[14] G. Cardoso, G. Marchesan, and L. F. F. Gutierres, "Recloser-fuse coordination protection for distributed generation systems: methodology and priorities for optimal disconnections," 12th IET Int. Conf. Dev. Power Syst. Prot. Copenhagen, Dinamarca, pp. 12.68-12.68, 2014.

[15] H. H. Zeineldin, H. M. Sharaf, D. K. Ibrahim, and E. E.D. A. El-Zahab, "Optimal Protection Coordination for Meshed Distribution Systems With DG Using Dual Setting Directional Over-Current Relays," IEEE Trans. Smart Grid, vol. 6, no. 1, pp. 115-123, 2015.

[16] M. Petit, X. Le Pivert, and L. Garcia-Santander, "Directional relays without voltage sensors for distribution networks with distributed generation: Use of symmetrical components," Electr. Power Syst. Res., vol. 80, no. 10, pp. 1222-1228, 2010.

[17] O. Anaya-Lara, N. Jenkins, J. Ekanayake, P. Cartwright, and M. Hughes, "Wind Energy Generation: Modelling and Control". United Kingdom: Wiley Publications. ISBN: 9780470714331, 2009.
[18] J. P. A. VIEIRA, “Otimização de Controladores Utilizando Algoritmos Genéticos para Melhoria da Capacidade de Sobrevivência a Afundamentos de Tensão de Aerogeradores de Indução Duplamente Excitados” Tese Doutorado, Univ. Fed. do Pará, 2009.

[19] O. Gomis-Bellmunt, A. Junyent-FerrÉ, A. Sumper, and J. Bergas-JanÉ, "Ride-Through Control of a Doubly Fed Induction Generator Under Unbalanced Voltage Sags" IEEE Trans. Energy Convers., vol. 23, no. 4, pp. 1036-1045, 2008.

[20] Jing He, Qing Li, Shiyao Qin, and Ruiming Wang, "DFIG wind turbine modeling and validation for LVRT behavior," IEEE PES Innovative Smart Grid Technologies, 2012, pp. 1-5.

[21] IEEE Std 1547, "IEEE Standard for Interconnecting Distributed Resources with Electric Power Systems," 2009.

[22] MASON, R. "The art and science of protective relaying," United States: General Electric series. ISBN: 0471575526, 1956.

[23] IEEE Distribution System Subcommittee, "IEEE 13 Node Test Feeder,” 2001.

[24] GENERAL ELECTRIC. "Fuse saving schemes in feeder relays," United States: General Electric, 2002. 